\title{
Applying Social Media in Collaborative Brainstorming and Creation of Common Understanding Between Independent Organizations
}

\author{
Erno Salmela and Ari Happonen \\ Lappeenranta University of Technology \\ Finland
}

\section{Introduction}

This report is based on an experiment performed within the Johto (Innovative management of the supplier network and ICT systems) and Kiima (New business by strategic SME network) research projects funded by Tekes (the Finnish Funding Agency for Technology and Innovation). The experiment looked into the suitability of social media for content production and brainstorming work between organizations. According to Knight et al. (2008), the groups using web tools have showed an improvement in cohesion, but not as great an improvement as that found in face to face groups. They however suggest that web tools are valuable options to organizations that pursue benefits through virtual groups.

The organizations which participated in the experiment were research institutes/ niversities, consultants, service providers, and industrial companies. Almost all of these participants had some kind of linkage to the machinery industry. However, most of the participated organizations did not have any mutual business connections in the real world, but quite many of them knew each other through above-mentioned Tekes projects. In practice, we were dealing with an open innovation environment, which refers to a model of innovation in which firms draw on research and development that lies outside their own boundaries (Chesbrough, 2003). There were very heterogeneous group of organizations and people in this experiment. Grinyer (2000) writes that heterogeneous group (different personality types, backgrounds, training and education) can have positive effect on creativity and innovativeness. Furthermore, informal communication (such as social media mainly is) is considered to be one major factor to stimulate creativity in teams (Sundgren et al., 2005). As such, an aim of our study was to explore social media from the creativity (brainstorming) view of point in the independent company network.

The topic in the social media experiment was: "how to manage an idea process" (stages of the process, performance indicators, and incentives). The chosen topic was a new issue for many of the participant organizations, which is why a research oriented (exploratory) approach, seemed to be a good starting point for the experiment. In research network, the primary target of collaboration is the creation of new knowledge, while the research activities are carried out by every partner without a leading company (Magnusson and Nilsson, 2003). The experiment was performed during a two week period in the autumn 2010 and the web-based Yammer service (www.yammer.com) was used as a tool. 
Before starting working with Yammer, the facilitator (a researcher who worked in the Johto and Kiima projects) looked into the backgrounds of utilizing social media in business operations. This happened by participating in seminars that dealt with the topic (e.g. the Finnish National Innovation Forum, 2010) and by exploring earlier scientific articles. This was done to acquire initial information (e.g. good practices and encountered challenges) of using social media in a networked business environment, and how social media is connected to knowledge management.

According to the earlier studies, the integration of networking into knowledge management generates different kind of benefits. Firstly, knowledge networks allow the firms to improve the access, the transfer and the integration of knowledge. Secondly, they are more able in generating knowledge than a single firm. Finally, knowledge networks enable companies to increase competencies to share common tacit knowledge. (Belussi and Arcangeli, 1998; Lorenzoni and Lipparini, 1999). Therefore, the knowledge management system moves from a single company point of view toward a network point of view (Canzano and Grimaldi, 2004). According to Sawhney and Prandelli (2000), the common inter-organizational understanding can be enhanced through collective learning. Simatupang et al. (2002) mention that through collective learning, the understanding of big picture can be improved. Activating people to produce content in social media seems to be challenging like the following use rates indicate: active users 1 per cent, respondents/commentators 10 per cents, and followers/absentees 89 percents of all users (Charles, 2006). A representative in a seminar stated that in one progressive ICT company the corresponding percentages were 2 , 16,82 , although a lot of effort was allocated for facilitating the content work. On the basis of the aforementioned relative portions it seems that the portion of passive participants is substantial. The facilitator of the Yammer experiment decided that these general ratios should be challenged in the Yammer experiment. In practice, it was estimated that a significant amount of work would be required to increase the portion of active users first to "sell" the experiment and later to facilitate the content work. This corresponds to view of Shahriza et al. (2005) who write that use of communication technology tool must be accompanied by proper training, sufficient technical support, and active facilitation. Especially active facilitation was seen important in Yammer work, because the good management of social interactions help to achieve common goals (Chen et al., 2008). Training and technical support were not considered as important because the Yammer tool was extremely easy to use.

When using social media, it is essential to get people to commit themselves to it. According to Breeding (2009), a commitment of resources ensures a steady stream of interesting content over a sustained period. This is important because when using social media it is important to keep the content up to date (Dymi, 2010). One of our seminar sources emphasized that the commitment should happen face to face or, at least, by phone - not by e-mail. The facilitator of the Yammer experiment utilized this perspective by striving to commit as many people as possible to the experiment by describing its objectives face to face or by phone. On the other hand, the aim was to find out what significance it has on the participation and content production activity if the introduction is made only by e-mail.

Committing people to the Yammer experiment was beforehand seen as challenging, because the facilitator could not use traditional management methods as people participated in the experiment from different organizations. For example, Crawford (2001) writes that enforcement can be a mean to promote the active utilization of electronic communication tools. This kind of management was impossible in our Yammer work because of above- 
mentioned reason. Another challenge was how to find the common issue which gets people from different organizations interested. As a result of these challenges, the facilitator estimated that first the focus has to be on selecting a topic which interests different parties. Secondly, the participants should be managed especially through motivation.

One representative in a seminar emphasized that agreeing on objectives, intermediary objectives and schedules is important in any work performed in social media. This point of view supports the opinion of Phillips and Phillips (1993) that the content learning process must have a well-defined beginning, middle and end. Furthermore, the shared goals for the group serve as a bonding mechanism that helps different partners to combine resources and facilitate the communication (e.g. exchange of ideas) and achievement of common understanding (Tsai and Ghoshal, 1998; Inkepen and Tsang, 2005). One speaker in a seminar who had operated a lot with social media stated that although their own business offers social media consulting services, it took them a year before they learned to utilize social media properly. In addition, the individual in question emphasized that technology is not the problem when applying social media. Instead, the problems are caused because the aims of using social media are insufficiently discussed. In addition, the same person stated that transparency is a good way to get people to produce content in the agreed schedule. One way is to display who has delivered the agreed content on the agreed schedule to all participants of the social media service. In this situation, it can be said that community pressure guides people to produce content on time. On the basis of this viewpoint, the facilitator made beforehand a rough plan of the Yammer experiment including objectives and schedules and, in addition, decided to utilize extensive transparency in the experiment. All of the above presented viewpoints were based on utilizing social media either inside a company or in operations between partners. This differs significantly from our Yammer experiment, in which most of the organizations did not co-operate in the real world. This was, as estimated beforehand, one of the most interesting challenges in our experiment: how to get people who are "strangers" to each other to participate and actively produce content together? Furthermore, the experiment was dominated by a special situation since the participating organizations did not have a concrete goal, from the viewpoint of their own organizations, for the Yammer work. Instead, the experiment had two exploratory goals on one hand to get more information on managing an idea generation process and, on the other hand, to gain experiences on using social media in business operations among independent organizations.

\section{Experiences of the Yammer experiment}

This chapter presents the main stages of the Yammer experiment - preparatory work, registering stage, use/working stage as well as the content created in the experiment on a rough level.

\subsection{Preparatory work}

Before starting the experiment, the facilitator made a rough plan on how to proceed during the next two weeks and what results would be pursued from the experiment. As it is mentioned earlier, the initial stage of the development process, managing an idea process, was chosen as a content topic in the experiment. This choice was influenced the fact that it was found out both in the Johto and Kiima projects that there seems to be development needs in this process in studied companies. 
In the preliminary plan, the first Yammer week was reserved for general discussion on the idea process management. Performance indicators and incentives of the idea process were chosen as the more specific content topic. The aim was to contemplate them during the second Yammer week with the help of brainstorming. The goal of the brainstorming was to gain such good process descriptions as well as indicator and incentive ideas that some of the companies participating in the Yammer work would become inspired to refine them further for their own practical operations after the Yammer period. However, the content of the second Yammer week was left somewhat unplanned, since the purpose was to ask the users after the first week which contents they would especially like to concentrate on during the second week.

Before starting working with Yammer, the facilitator had reserved time for producing preliminary contents, so that the invited persons would have interesting conversation openers when they arrived at the Yammer for the first time. In addition, content was requested from four other researchers that participated in Yammer work. The goal was to receive two conversation openers from each researcher in advance (altogether eight openers) before sending invitations to the other Yammer participants. There were altogether only two openers (plus two from the facilitator), which was a disappointment to the facilitator - "what might be the enthusiasm of corporate representatives towards the matter if even the 'inner circle', the researchers, do not produce the requested content". This was, from the point of view of continuation of the experiment, the first critical point. At this stage, the facilitator even pondered whether it would be worthwhile giving up the experiment altogether - a so called surrender point 1 .

The facilitator presented the objectives, schedules and principles of the experiment beforehand to 13 persons face to face, four persons by phone and 15 persons by e-mail. This introduction took place about two weeks prior to starting the use period, so that it would be possible for people to reserve time for the Yammer work in advance. For two individuals interested in the matter (they were included in the previously mentioned 15 persons who received the introduction via e-mail), the Yammer experiment was presented when it was already underway. Thus, the experiment was presented to 32 individuals, all of whom received an invitation to Yammer. Facebook was familiar to the majority of them from leisure time, but for professional purposes social media had been rarely utilized. In fact, Yammer was chosen as the tool for this experiment due to the resemblance of its user interface to Facebook. Thus, it was estimated that Yammer would be easily adopted by the users, so the success of the experiment would not, at any rate, depend on the user friendliness of the application.

\subsection{Registering stage}

Altogether 25 persons from 14 different organizations registered to Yammer: 10 companies, three universities/research institutions, and Tekes. In the context of the introduction, the facilitator inquired after the people's interest in joining the project of producing Yammer content. At the same time the facilitator additionally estimated the interest of the people towards the matter on the basis of their "body language". Naturally when using e-mail, this was not possible to observe and only two from the invited persons announced that they are interested the Yammer experiment. On the basis of the number of invitees and estimated level of enthusiasm, the presenter set a goal for the number of registered users. The set objectives were that 10 of the 13 persons whom had received the introduction face to face would be registered and, respectively, two out of four who had been introduced by phone 
and five out of 15 who had been introduced by e-mail would be registered. Thus, the goal was 17 registered users in all. The actualised number (25) clearly exceeded this goal. From those who had received face to face introduction, 11 persons registered, and from those who had received introduction by phone, three registered, so in these the realizations corresponded well to the objectives. Instead, the registration rate of those who received the introduction by e-mail was a positive surprise, since 11 out of 15 registered. On this basis it would then seem that interest towards working with social media can be awakened also via e-mail.

It is also interesting to observe the accumulation of registered users during the two week use period. Within two days after sending the invitation, 13 persons had registered into Yammer. Ten out of these individuals registered already on the first day. After this, the facilitator sent three notifications every two days for the unregistered persons. To lure new users the notifications included extracts of contents (most interesting topics) that had been discussed in Yammer so far. Furthermore, information on forthcoming Yammer work was attached to the e-mail. After the first notification, three more registered within two days. After the second notification, five more registered within three days and, after the third notification, four more users were gained. Thus, in the beginning of the second week all 25 registered users were involved. Based on these results, the e-mail notification was reasonable to do. However, what must be noted here is that from time to time Yammer sent automatic messages to those invited who were not yet registered. When asked afterwards, at least two persons had registered to Yammer because they wanted to get rid of the constant registering requests sent by Yammer. Figure 1 views the development of the number of users during the Yammer experiment. In addition, the image shows the e-mail notification dates for unregistered users.

Based on the registration rate, people seemed to be interested in this experiment. This is also supported by the comments received from users. The following are a few examples:

"It will be interesting to see how this works and what kind of content there will be. Also the functionality of the technique is interesting."

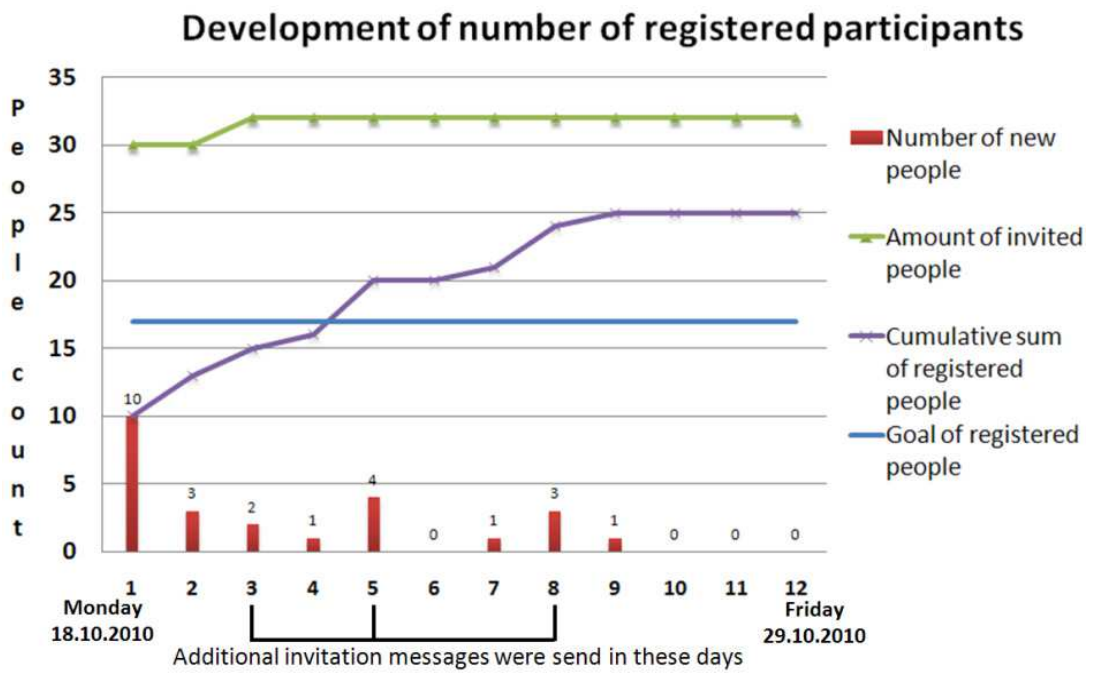

Fig. 1. The development of the number of registered users on Yammer 
"When I received an invitation, interest towards this type of experiment arouse instantly. If the strengths of this are utilized properly, this is in some way in the middle of face-to-face communication and anonymous communication. Naturally one also wants something to be reserved for the employer. I am sure that with this group of people we can create something which can be used to once more further refine matters that are actually productive in practice."

"I've got three main incentives for this. First, to find with this group a couple of good ideas on indicators and incentives which can be further refined to receive a new production model for the practice of the Finnish industry. Second, to gain information on how social media could be utilized in the development work of the Finnish industry of small and medium sized enterprises. Third, to find people who think alike and with whom I could co-operate even more in the future."

On the basis of the previous comments, gaining experiences of the suitability of social media in business operations seemed to be as important for users as the discussed topic.

\subsection{Working stage}

This chapter focuses on the experiences gained during the Yammer work period which lasted for two weeks. As mentioned earlier, the first week concentrated on the more general matter in creating a common understanding of the management of an idea process, whereas in the second week the purpose was to handle more specific topics. In the rough plan, the possible theme of the second week was indicators and incentives of an idea process, but the actual theme choice was, however, a collective decision. After the first half of the first week, an enquiry was realized in Yammer about which contents the participants especially wanted to concentrate on during the second week. Table 1 presents the results of this enquiry.

\begin{tabular}{|l|c|}
\hline $\begin{array}{l}\text { What issues would you like to be handled in Yammer during the } \\
\text { second week? }\end{array}$ & $\begin{array}{l}\text { Portion of } \\
\text { the respondents }\end{array}$ \\
\hline General issues related to constant improvement and innovation & $7.5 \%$ \\
\hline Good indicator and incentive practices to be found & $23 \%$ \\
\hline Concrete indicators and incentives for development & $62 \%$ \\
\hline Something else & $7.5 \%$ \\
\hline
\end{tabular}

Table 1. Enquiry of subject matters handled during the second week

Altogether 13 answers were ultimately received for this enquiry. Discussing concrete indicators and incentives received the most support, so it was chosen as the main theme for the second week. Good indicator and incentive practices were regarded interesting, as well, so they were also decided to be covered during the second week. This enquiry was additionally used as an indicator of the users' activity level. After publishing the enquiry, only five people out of the 25 registered users answered it within 1.5 days. The small share of respondents frustrated the facilitator - "I wonder if this Yammer business is worth continuing, since people don't even answer a simple enquiry, in which we decide on the focus points of working for the second week." Another possible surrender point, but the choice was to continue. By notifying about the enquiry by e-mail and raising the enquiry as the top point of the Yammer user interface, considerably more answers were received within the following 1.5 days - "13 answers is an OK level".

The outcome of the first Yammer week is well illustrated in the summary published by the facilitator to the Yammer users: 
"First of all, there are 19 registered users. Altogether 32 individuals were invited and nearly half of them received a notification only by e-mail. I am very satisfied with this interest towards the matter. It's difficult to evaluate how much the active users follow the contents since there are no statistics available. Instead, there is more specific information on the more important matter, namely content production. There are nearly 200 comments in all. I was going for a somewhat more balanced content production, since the content production was pretty much in the hands of a couple of fellows. Towards the end of the week the direction was, however, for the better, which meant that more opinions were becoming visible. Hopefully the same continues next week, as well, because it enriches the contents.

The content sprawled very much this first week, but I do not consider it as a bad thing at all. This is because it improves the formation of an overall picture, which is what this thing is all about. In the coming week we will then go into those two topics more specifically, namely concrete indicators and incentives as well as good indicator and incentive practices to be found.

I wish everyone a good weekend and let's continue on Monday. Although I'm sure some nerds will come by during the weekend, as well $:$;... now it seems there are 20 of us, so welcome, Harri."

When measured by the number of comments, a little more content was created in Yammer during the first than the second week. The main reason for this was that during the second week the focus moved from a more general discussion of the topic to a more specific topic. A brainstorm was organized in Yammer in order to generate ideas on indicators and incentives. The results of this brainstorm are viewed next.

\subsubsection{Experiences of the brainstorm performed in Yammer}

For the brainstorm, the facilitator made a briefing and distributed it to all persons invited to Yammer. Together with the briefing, the following "motivational e-mail" was sent to the users:

"During the second week of Yammer, a web brainstorm will be held on the indicators and incentives of an idea process. During the first week, Yammer worked pretty much as a traditional network teaching environment with interactive features. This network teaching environment matter can be a completely new thing for a part of you, but when inspected from a wider perspective it is not a revolutionary thing, as there has been plenty of similar experiments abroad and in Finland. This brainstorm, however, is a big deal - especially as the object of inquiry is a very complex matter and there are not a lot of prior practical experiences anywhere. It is clear that for this to succeed a lot more active input is needed from this group than there was during the first week. In this brainstorm we have the opportunity to disprove the assumption that it is easier not to participate in a brainstorm online than in a traditional face-to-face meeting. At the same time, it has been said that ideas that are considered and written down calmly are better than ideas "tossed around" in a traditional meeting. Let us, then, prove this assumption right!"

The users were asked to return their ideas within two days to the facilitator's e-mail. This was done in order to prevent "copying" other people's ideas, which would have been possible if the users had published their ideas directly into Yammer. After receiving the ideas, the facilitator published them as such at once in Yammer. There were 5 idea packages received by the deadline - surrender point number 3. No giving up - "at this stage, it is not worthwhile to stop". However, teeth were grit and the facilitator sent a somewhat provocative e-mail (a part of this below) to the users who had not yet returned their ideas.

"25 registered users - five idea packages received; the same activity relation others have reached with social media. Should we, then, be satisfied to reach the same level of activity than everyone else? Perhaps, but personally I am a little bit disappointed, since I had a strong belief that this group can do considerably more and I still believe it. I am especially annoyed on behalf of the few 
fellows who have properly invested in the idea generation. Let us take this day as extra time for pondering ideas and then we'll see where we stand. We are not, in fact, far from the situation where we can proudly present together what we have accomplished. But this requires one more final push."

After this e-mail, one idea package more was received, so altogether six individuals participated in the brainstorm. Beforehand, the facilitator had set the participation of eight individuals in the brainstorm as an objective, so this was not quite reached. However, the facilitator included some ideas which came forward in the first week's Yammer discussions to the results of the brainstorm. As a result, the ideas of four more users were gained, so altogether the ideas of ten users were visible in the results of the brainstorm. The received ideas ranged very much with regard to their refinement grade - from a couple of quickly scratched ideas all the way to complete indicator and incentive concepts. The facilitator asked the participants of the brainstorm how much time they had spent working on their ideas, and it ranged remarkably - from 15 minutes to 3.5 hours.

From the ideas born in the brainstorm, five were taken to be further refined in Yammer - on one hand, the individual ideas which were most recurrent and, on the other hand, the most unique, were chosen to be further refined. There was altogether 2.5 days for refining and commenting on the ideas. Related to the refinement of the ideas, 25 comments from five individuals were received. This fell considerably short of the goal set by the facilitator, since the objective was to get at least 50 comments from ten different users. The activity of the users in refining ideas was very much equivalent to the level of the more general conversation held in Yammer during the first week.

In connection with the brainstorm, a small competition was organized between the users in which the creator of the best idea would be awarded with a bottle of wine or a restaurant gift certificate. This was not believed to have a strong motivating influence on creating ideas, but rather it was seen as an extra spice appropriate to the subject matter. The name of the producer of the best idea was announced to the users in Yammer as well as by e-mail. In addition, the name of the producer was mentioned in the meeting of the Kiima steering group, which caused applause to the rewarded person. A small matter, but surely especially the latter acknowledgement felt good to the winner. In addition, the red wine was reputedly excellent - "long and good aftertaste is the best quality of this wine"-).

\subsubsection{User activity in the Yammer work}

In Chapter 2.2 it was presented that interest towards the Yammer experiment was measured with the registration rate. The facilitator had an advance presumption that an interest in the matter is not yet enough for users to actively follow the content or especially to produce content. For content production, both strong commitment and real enthusiasm are needed both towards the subject matter and toward writing online. Commitment was a challenge in this experiment, since the network community comprised of different organizations, which meant that the facilitator could not demand anyone to invest in the matter. In addition, people had different interests towards the experiment, so there was no clear common goal. It was not an easy matter to manage the researchers, either (see surrender point 1 presented in Chapter 2.1).

In the experiment, a free version of Yammer, which contained quite few use report options, was used. Two important reports could, however, be found related to the actions of the users. First, Yammer automatically produced report data of the overall number of comments as well as the number of comments of each registered user, which described the userspecific content production activity. Naturally the facilitator and also other users saw also 
all the new comments published in the service. Secondly, people who had signed in could be seen in Yammer constantly. On this basis, the facilitator could evaluate the number of users who had signed in. However, compiled reports could not be retrieved on how often the users were signed in and how they used the service (e.g. how often they signed in or how much they read the contents produced by others).

User activity was measured on two main levels: the level of following conversation and the level of content production. As mentioned above, there were no accurate statistics available on the users' visits and how actively they followed conversations in Yammer. Findings suggest that the number of people signed in at the same time varied during day time between six and 13 individuals. The names of those who had signed in could be seen in Yammer, so information on who were the most active individuals could be gained, as well. Although it seemed that three individuals had Yammer open the whole time, since they were signed in during the evenings, as well. According to the findings of the facilitator, some of the registered users were present in Yammer only a few times or a few of them perhaps not even once. The facilitator estimated that there were altogether 7-10 users (about $30-40$ per cent of the 25 registered users). Afterwards received user feedback proved this estimation to be right

Information about the content production in Yammer was obtained well. In every published comment, the name of the writer of the comment was automatically visible, so it was easy to identify the writer of each comment. In addition, Yammer made a notification of each new comment separately with a red font in the upper part of the page, so the publication of new contents could be seen fast. It would also have been possible to have each new comment sent to the users' e-mail, but this was thought to be a too frequent notification interval. Instead, a summary of new contents to be sent at the end of each day to the users' e-mails was chosen. During the two weeks, contents were published by 15 individuals ( 60 per cent of all registered users), who produced altogether 350 comments. Figure 2 shows the content production activity of different users measured by the number of messages as well as the cumulative growth in the number of messages per user.

Three of the most active users produced approximately 75 per cent of the comments, four of the most active about 85 per cent, and eight of the most active about 95 per cent. The minimum objective set in advance was that $4-5$ individuals would produce 80 per cent of the contents, so this objective was nearly reached. By the middle of the first week, two of the most active users (another of them was the facilitator) had produced about 80 per cent of the contents, after which the facilitator tried with different activation methods (e.g. by asking questions) to increase the activity of others. This was somewhat successful, but still it seemed to be quite difficult, since seeing these people face to face was not possible during the working period. Among the most active content producers (8 individuals with the minimum of 5 comments), for seven people out of eight the Yammer experiment was introduced face to face or by phone and for only one by e-mail. It would therefore seem that the introduction method of the Yammer experiment had an influence in the content production activity. Instead, the method did not seem to have much significance on the registration rate, as stated in Chapter 2.2.

There were altogether 30 conversation openings in Yammer. However, this is not essential information, since inside the conversation paths the discussion covered many different topics, which is typical for an online discussion. For this reason, no conclusions can be made of the importance of the topic/discussion opening in question on the basis of the number of comments in individual conversation paths. In any case, the facilitator opened new 
conversation paths for the most interesting comments which deviated most from the original topic and which had been published inside the existing conversation paths. In the Yammer experiment, the facilitator opened 20 conversation paths out of 30 .

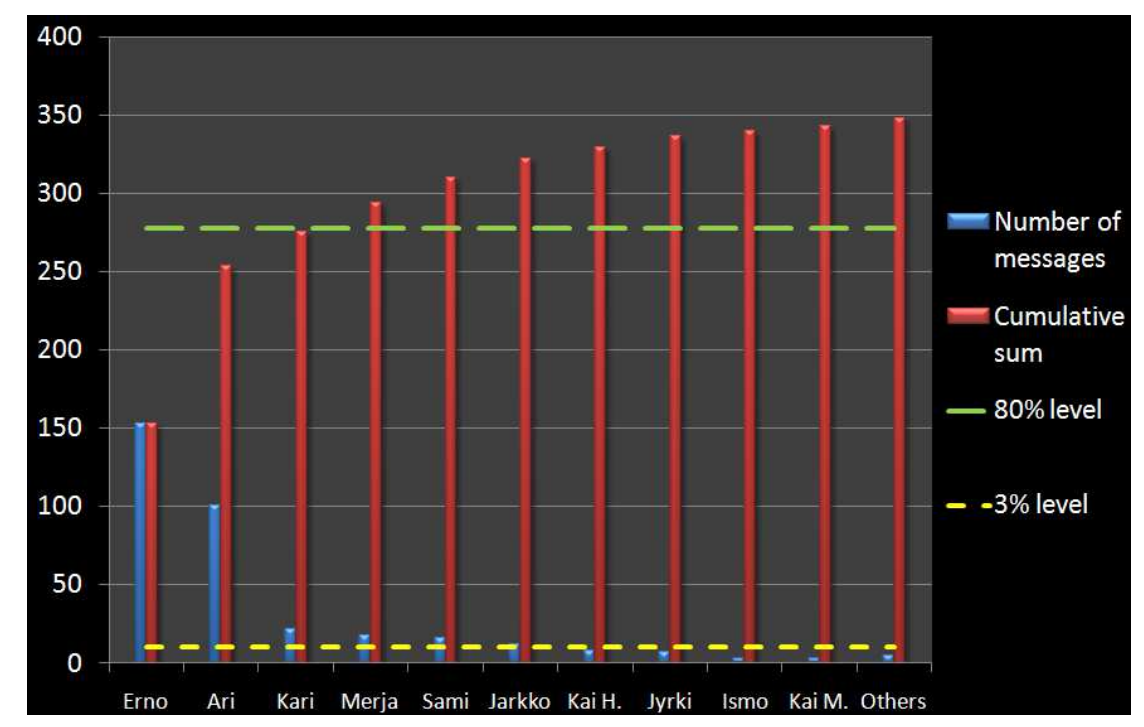

Fig. 2. The number of messages per user and cumulative number of messages

When we compare the user activity of this experiment to other experiments of social media in business operations, this was a successful experiment. In Chapter 1 it was told that when applied in business operations, there are typically 1 per cent active users, 10 per cent answerers/commentators, and 89 per cent followers/absentees in social media. In our Yammer experiment the corresponding percentages were: 8 per cent $(2$ users who published content every day), 24 per cent (6 users who were signed in approximately every other day and produced at least 5 comments in Yammer), and 68 per cent ( 17 users who produced less than 5 comments; roughly half of these 17 users were absentees). These percentages are not directly comparable to the previously presented typical percentages, since the grounds for measurement are not specifically known. Regardless, they are certainly indicative. In absolute terms, the numbers of active users in our Yammer experiment are not very flattering, either. At the same time, as a point of comparison we must keep in mind that everyone is not equally vocal in face to face meetings, either.

\subsection{The content produced in Yammer}

At the end of the Yammer work, the content was moved into Word and, as a result, a total of 67 pages were gathered. In the free version of Yammer, the content had to be manually pasted into Word which was quite laborious - especially when the layout of the content had to be cleaned so that the format would be as readable as possible. Also "copy pasting" took time because, in addition to opening different conversation paths, the longest messages had to be opened individually so that they were completely visible. In chargeable Yammer versions, the content can be exported into a file. In addition, indicator and incentive ideas were created in the brainstorm performed in Yammer and these were published by the users 
in separate documents instead of Yammer. These created about 30 pages of additional content. Therefore, altogether about 100 pages of contents were produced as a result of two weeks of Yammer work. The volume of content production was not measured on the basis of the amount of writing (number of characters or words) per user, but that would be one measurement possibility.

The quality of the content is naturally more important than the quantity, but also considerably more difficult to measure, since the quality is a very personal attribute; different people appreciate different things. This was true also among the Yammer users, since the users had different expectations and interests towards the Yammer work. Qualitative measuring was performed in practice so that, after the experiment, the users were asked about their views on the content. The following is a compilation of some of the received feedback. What is noteworthy in the feedback is that it is not necessarily targeted at the actual topic which was discussed, but also at the possibilities of working online in general.

"From the point of view of a scientist, it came to mind that this very easily created a ready, transcribed interview material, the kind of which makers of qualitative research normally gather by interviews, recordings and then by transcribing it to a written format and, finally, by analyzing it. Now those first three stages were created at the same time. Now systematic methods of content analysis of qualitative research could be used for the material, as well.

"This is an extremely good content package. If we would now imagine a situation in which a larger group has a corresponding discussion in order to develop some part of business life or otherwise, the whole conversation would be saved. This kind of a capture of a conversation is not practically possible with e-mail communication or in any other way."

"When considering the time span, other work load of the individuals, and the voluntary nature of the participation, I would say that the end result of the experiment is much better than I believe anyone expected."

The quality of the content created in the Yammer work can also be verified by the fact that the indicator and incentive ideas created in brainstorming evoked active conversation when they were tested a couple weeks after the Yammer experiment in a small group work organized in connection with a meeting of the Kiima project's steering group. At the time of writing of this report it seems likely that the ideas that were created will be refined even further with a few company networks. This shows that the conversation held in Yammer was current with regard to the needs of the companies and that it produced useful information for business purposes. At the same time, it is also interesting to see whether the organizations which participated in the experiment become enthusiastic about utilizing social media in the future in some way also in their own internal operations or partner network. Furthermore, the Yammer work was a starting point for one new research project that deals with idea process management in company networks.

\section{Facilitator's views on the Yammer experiment}

Some of the facilitator's experiences of the Yammer experiment were already presented in Chapter 2, e.g. in the form of the three surrender points, but let us consider this in more detail in this chapter, since the facilitator seems to have an important role in the application of social media. The facilitator and one research partner used altogether about 150 hours for the Yammer experiment. This consisted of preparatory work (familiarizing oneself with tools, making a rough plan, introducing the experiment to companies, and production of 
preliminary contents), facilitating the Yammer discussion and content production in Yammer, and writing reports (content report and this use experience report). The time used was distributed as follows between the aforementioned stages: preparatory work 20 per cent, facilitating the Yammer discussion and content production 40 per cent, and reporting 40 per cent. The effort was, therefore, significant, which explains the occasional inclination to surrender - especially when user activity was not quite at the desired level. The following is a presentation of the facilitator's views in the aforementioned main stages of the experiment.

\subsection{Preparatory work}

The preparatory work made by the facilitator was an important part of the Yammer experiment. Without thorough preparation the experiment would not even have been worth doing. The preparation undoubtedly had a significant influence firstly on the fact that so many of the invited users registered into Yammer and, in general, on the fact that there were so many individuals who wanted an invite. Setting the content theme, objectives and schedule beforehand was important since this made "selling" the experiment to companies considerably easier. Preliminary planning also helped during the Yammer work period everyone knew, at least to an extent, what they were doing, although according to the feedback received after the experiment people did have some mixed opinions of the exactness of the content definition. Let us return to this subject in Chapter 4.

\subsection{Facilitation and content production}

The main role of the facilitator during the Yammer work period was first and foremost to activate discussion or to get as many users as possible to produce good content. The facilitator strived to do this in different ways (e.g. e-mail notifications, highlighting the most interesting issues, setting tasks, votes, asking questions, and provocation). Visible advantage was, indeed, gained from this activation work, so it was definitely necessary work. Although it did take quite a lot of working time - "the expectations of the fruits of the activation work were higher than what was achieved".

The role of the facilitator was, in addition to the actual facilitation, to be very much also involved in content production. This was not in the line with the common view about the facilitator's role: a facilitator concentrates on process while the participants are familiar with the content (Phillips and Phillips, 1993). Before starting the working period, the facilitator decided to concentrate on guiding the content production and to slow down his own content production. However, this turned out to be too difficult when the subject was interesting "there was something to say to nearly all comments of other users". During the working period, the facilitator put on the brakes on content production a couple of times, but in these instances the conversation seemed to be stopping almost completely, which was not a good thing, either. At the end of the second week, the facilitator got a bit tired, as well, and did not have the energy to bring all thoughts forth in Yammer, although the facilitator would have had something to say - "the principle of reciprocity, meaning that if you give something, you should more or less get an equal amount back". The users did not give similar comments on whether one reason for the small amount of content production could have been that users did not want to share their own knowledge of the subject matter with others. According to the facilitator's evaluation, this may have been possible with regard to a few persons at most. In any case, this was undoubtedly not the most important reason for the small content production activity. Let us 
return to the other reasons in Chapter 4. The Yammer work period did not fulfill the facilitator's expectations with regard to the activity of the users, which is why the facilitator was somewhat disappointed after the period. The following moods illustrate the facilitator's feelings immediately after the Yammer work period:

"Psychologically facilitation online was considerably harder than in face to face meetings. There were, indeed, three points in which I would have liked to call off the game."

"I will never do this again... or not in at least five years."

"In social media, we cannot properly see others' reactions to the matter and we do not even know who are actually present, although their names could be seen in the list. When facilitating or writing the content, many times I had a feeling of standing in an empty room talking to the walls."

New user comments were practically the only thing that gave the facilitator information about the users' reactions, which is very little, since on average there were only about 20 user comments per day, excluding the facilitator's own comments. At the same time, the Yammer work also included some content floods. One of the active content producers said that these were enjoyable moments:

"From time to time the same kind of enthusiasm could be detected as in the best face to face meetings. The comments streamed in such a pace that one did not have the time to finish writing one's own."

Immediately after the work period, the facilitator found it very difficult to evaluate the value of the Yammer experiment, since there was quite little feedback during the experiment and after it. Feedback was requested by e-mail from all registered users immediately after the Yammer work period. In retrospect, it might have been worthwhile to organize a round of phone calls with the users after the experiment, so that information on the users' views could have been better received. However, 1-2 months after the working period the facilitator has discussed the matter with about ten users either face to face or by phone. Their feedback has been "cautiously" positive. On the basis of the feedback received, the feelings of the facilitator were eventually positive, which means that the experiment was worth doing. At the time of writing this, the following idea illustrates the facilitator's feelings well: "Perhaps I will facilitate a similar thing again already after a year... why not even after a couple of months with a smaller group."

\subsection{Reporting}

Originally, no reports were planned of the Yammer experiment, but when the experiment had ended, reporting the results was seen as necessary since both the content created in Yammer and the use experiences gained on utilizing social media were seen as useful also for others than those involved in the experiment. The content report can be utilized in the future as an information source for idea process and innovation management (in fact the report was one source for earlier mentioned new research project). Furthermore, as to the power of social media, one can notice just by eying the report what a large amount of information was in the end created during two weeks by 15 content producers. The present use experience report is useful to companies also in the sense that as they start their own application of social media, this report provides analyzed background data of important issues to be considered, so that the worst pitfalls can possibly be avoided.

\section{The opportunities and challenges of social media}

This chapter views the opportunities, benefits and challenges of applying social media in communication among different companies on the basis of the Yammer experiences. 


\subsection{Opportunities and benefits}

In our Yammer experiment, no actual, specific development work was conducted, but a group of organizations discussed together the development opportunities related to the chosen theme. The organizations who participated in the experiment had different interests towards the experiment. For a part of the participating organizations, the management of an idea process was a genuinely current topic, and practical actions have already been taken in this area. For some of the organizations the matter was new, so the representatives of these organizations were mostly searching for further information on the topic. For some of the persons involved in the experiment, the topic in itself was not the most important thing, but they were more interested in the application opportunities of social media. Therefore, it can be said that the experiment included quite a dispersed group of representatives, which was not necessarily the best possible setting. Basically, a similar experiment could have been made separately for the three aforementioned segments, in which case the interests would have been more coherent inside the groups. Thus, it could be said that organizational aspect is an essential part of working with social media.

As there were no prior business connections between the companies and due to the aforementioned differences in interests, there could not, in practice, have been a concrete development target in the Yammer work. At the same time, the topic of the experiment was new to most, as well, so there was not really any basis for practical development. Therefore, the goal of the experiment was first and foremost to increase the participants' understanding of managing an idea process as well as to find the most important factors which should be taken into consideration in developing an idea management process. Thus, this was very much like a research approach to the topic or, in other words, a foundation was created for practical development work in the future. For this type of work, social media seem to be suited very well. With the help of social media people can, for instance, quickly spread information on good practices in different companies and networks and, thus, gain new ideas for their own organization. On another hand, it could be necessary to arrange face to face meetings along side with work in social media. Shahriza et al. (2005) mention that high performance is associated with the utilization of both face to face and virtual communication for group work; effectiveness and performance cannot be ascertained solely by looking at either face to face communication or ICT exclusively. According to them, the face to face meetings may be more effective when all members are available and when the tasks are highly ambiguous.

To succeed in social media working, it is important to carefully define the subject at hand. The topic of this Yammer experiment may have been too wide and challenging for an online discussion, which possibly had an influence also on the users' content production activity. The following user comment illustrates this: "In addition to the incompatibility of schedules and other hurry, the greatest obstacle for participation was the extent and vagueness of the theme. It was hard for me to create an idea process for a situation which kind of works anytime, for anyone, and for any organization. Of course there are and should be generic models, but in this instance I experienced it as challenging which meant that my head was completely empty."

This comment is related to the previously mentioned organization matter, meaning that the user group was probably too diverse with regard to interests. Discussing issues on a general level is typically related to the research approach used in this experiment. Case-specific sessions could also have been organized in Yammer (e.g. developing an idea process for one company or for its network), but beforehand the facilitator estimated that this would not be sensible with a group that included numerous independent organizations. Instead, after the 
experiment the facilitator suggested a possibility to start developing a detailed idea process with a smaller group, for instance by applying Yammer, if there is a company interested in this matter. Hopefully this kind of an experiment will be made. It is quite possible, since 4-5 individuals who participated in the Yammer experiment stated that they are interested in the matter (not only when it comes to developing an idea process, but also developing any other interesting topics). This kind of small group size appears to be quite suitable for actual development work. This corresponds to Grinyer's (2000) view that the effectiveness of a communication declines as the size of the group increases

When it comes to defining the topic, it can be said that the topic had, in fact, been quite specifically defined beforehand (process stages, indicators, and incentives of an idea process). However, it became very quickly obvious in the conversations that there was need for discussing the topic from a wider perspective; the participants wanted to discuss, for instance, the innovation culture as well as the differences in continuous improvement, incremental innovation and radical innovation. The majority of users wanted, therefore, to understand the backgrounds of the matter, which is typical when the issue is new. At this point, the facilitator did not want to return the conversation back to the topic defined in advance since there was clearly a need for an increase in the general understanding of innovation operations.

During the second week, a brainstorm as well as refinement of the created ideas was tried out in Yammer. The test did not exactly provide an answer on how well social media are suited for brainstorming. However, some users did produce good ideas, and they have been further refined with companies, so the brainstorm was useful in any case. The majority of users did not produce any ideas, though. It was possibly easier not to participate in a brainstorm in Yammer than in face to face meetings.

Based on Yammer experiment, utilizing social media seems to have at least the following benefits compared to face to face meetings:

- getting such people together "at the same table" whom it would not be possible to bring together otherwise; thus, it is possible to gain knowledge outside the inner circle (corresponds real-life open seminars)

- $\quad$ ideas are usually refined when they are written down

- the discussion is documented in one location

- "quiet" persons can bring their thoughts out in the open better

Social media will undoubtedly become an integral part of the operations of companies, but even with this we need to learn in stages. The facilitator has experiences which go back ten years on discussion group experiments conducted in individual companies. These experiments failed completely at the time because not enough people were involved. On the basis of the Yammer experiment, the development compared to that time has been considerable since 25 out of the 32 people who were invited from different organizations participated voluntarily in Yammer. As the learning processes are constantly becoming faster, in five years social media will probably be natural communication methods also in business. By that time perhaps all 32 invited individuals will register and 20 of them will participate in the discussion actively. However, before that there is work to be done. First, it is good to experiment what social media are all about. For that, a Yammer experiment like the present one surely gave some foundation, but the next step could be to consider how social media could be utilized in one's own operations. After this, do not postpone the experiment - after all, this matter requires learning and gathering experiences like any other. 


\subsection{Challenges and obstacles}

The Yammer experiment revealed that there are numerous challenges and obstacles in applying social media among organizations and online writing in general. On the basis of the feedback, lack of time was the most essential limitation especially when it came to content production. The facilitator and his research partner were in practice the only ones who had reserved sufficient time for Yammer work in advance (at least a couple of hours each day), even though others also knew of the timing of the discussion already a couple weeks in advance. Either they did not consider the matter to be especially important or the time needed for a profound participation surprised the users. This is well illustrated in the following user comments:

"It must be stated that as interesting as these topics were, following them and commenting on them takes some time... it is so damn busy at work at the moment."

"I was on a sick day, so I grabbed the computer and spent the day in Yammer. At work I have not been possibility to take part in it at all."

"At the moment, both work and my own time are at such a challenging point that I have not had much chance to get involved in this Yammer after the first week. With the help of sufficiently early scheduling, matters could be organized so that one could participate more in this sort of thing."

"It is difficult to follow this during the work day. It is irritating. I'll try to participate today..."

In addition to lack of time, the Table 2 introduces challenges and obstacles in applying social media were detected on the basis of the Yammer experiment.

\begin{tabular}{|l|}
\hline Less than ideal organization; the group had too varied interests \\
\hline $\begin{array}{l}\text { People do not want to repeat the same contents (when there was not time to read contents } \\
\text { of other users) }\end{array}$ \\
\hline The written comments leave a mark (self-censorship) \\
\hline Content production is slow \\
\hline Everyone's writing skills are not the same \\
\hline $\begin{array}{l}\text { A person who is good verbally can think that the online environment puts a damper } \\
\text { on the atmosphere since his own characteristics do not come out }\end{array}$ \\
\hline The environment in which one is writing can be challenging (e.g. open office) \\
\hline Negative prejudice towards online communication \\
\hline A written text does not depict emotions which is an essential part of communication \\
\hline
\end{tabular}

Table 2. Observed challenges and obstacles of social media based on Yammer experiment

\section{Summary}

25 participants from 14 different organizations participated in the social media experiment. The topic of the discussion was the idea process management, which seems to be a current topic for companies. Because the topic was a new matter for the participant organizations, the choice of a research method in the Yammer experiment. According to study the chosen method and application of social media seemed to be a good approach in order to increase common understanding between the independent participants. On the other hand, the study did not exactly provide an answer on how well social media tools are suited for brainstorming. Further research is needed on how social media can be applied to 
brainstorming. In addition to the chosen topic, the organizations were at least as interested in gaining experiences of applying social media technologies in their business operations. To respond this knowledge need, the utilized free version of the web-based Yammer tool turned out to be a very good and easy-to-use tool.

The success of the experiment was measured with the registration rate of the invited individuals, content production activity as well as the quality of the content created in the experiment. The registration rate was a positive surprise since 80 per cent of the invitees registered into Yammer. This showed that people were interested in the experiment. However, the activity of the content producers was quite low, which reveals a lack of real commitment towards the experiment. The four most active content producers produced about 85 per cent of the contents when measured by the number of comments. In practice, the biggest reason for the lack of content production was lack of time: the users had not wanted or known how to reserve sufficient time for the experiment in advance. At the same time, the user group had quite varied interests which probably weakened the motivation for content production. This seems to be in line with the observation of Walker and Ellis (2000) and Studt (2004) that having shared goals is an essential aspect in development and innovation work. Furthermore, a lack of knowledge towards the discussed theme was one reason for small content production activity. In any case, the activity figures surpassed many other experiments with social media as 8 per cent of the users were active content producers and 24 per cent were commentators in the Yammer experiment (compare to corresponding 1 and 10 per cent mentioned by Charles, 2006).

The quality of the created content was evaluated on the basis of user feedback and it was mainly evaluated as good. In addition, a good indicator of the quality of the content is that a part of the content created in the Yammer work has later been refined with the companies, the goal being to develop management practices of the idea process. Furthermore, the created content was utilized as source information for a new research project.

Resources had been sufficiently reserved for the facilitation, which was clearly an important part for the success of the experiment. Both the registration rate and content production activity would have certainly been considerably lower without careful facilitation. Facilitation was needed in the preparatory work (e.g. planning of experiment and getting users to commit to the experiment), guiding the content work, and post-treatment (e.g. taking care of necessary further actions and reporting).

To summarize, social media are suited for communication between independent organizations but at the moment we seem to be at the early stages of learning curve when it comes to it. In the coming years, social media will be natural communication tool also in business, which is important in order to reach a critical, content-producing user mass. The following comment from a user of the Yammer experiment illustrates the possibilities of social media well: "For social media, there is clearly a new type of a void to be filled in business. This is not about replacing the current process, but about a new process.

\section{References}

Belussi, F. and Arcangeli, F. 1998, A typology of networks: flexible and evolutionary firms, Research Policy, Vol. 27, pp. 415-428.

Breeding, M. 2009, Social Networking Strategies for Professionals, The systems librarian, October. pp. 29-31. 
Canzano, D. and Grimaldi, M. 2004, Knowledge Management and Collaborations: Knowledge Strategy and Processes in the Knowledge Networks, Proceedings of IKNOW'04 Graz, Austria, June 30 - July 2, 2004.

Charles, A. 2006, What is the $1 \%$ rule?, The Guardian, Thursday 20 July.

Chen, M.-H., Chang, Y.-C. and Hung, S.-C. 2008, Social capital and creativity in R\&D project teams, R\&D Management, Vol. 38, No. 1, pp. 21-34.

Chesbrough, H.W. 2003, The era of open innovation, MIT Sloan Management Review, Vol. 44, No. 3, pp. 34-41.

Crawford, C.M. 2001, Developing webs of significance through communications: appropriate interactive activities for distributed learning environments, CampusWide Information Systems, Vol. 18 No. 2, pp. 68-72.

Dymi, A. 2010, Servicers Use Social Media To Create New Opportunity, National Mortgage News, May 17.

Grinyer, P.H. 2000, A cognitive approach to group strategic decision taking: A discussion of evolved practice in the light of received research results. Journal of the Operational Research Society, Vol. 51, pp. 21-35.

Inkepen A.C. and Tsang, E.W.K. 2005, Social capital, networks, and knowledge transfer, Agademy of Management Review, Vol. 30, pp. 146-165.

Knight, M.B., Pearson,J.M. and Hunsinger, D.S. 2008, The Role of Media Richness in Information Technology Supported Communication inGroup Cohesion, Agreeability, and Performance, Journal of Organizational and End User Computing, Vol. 20, No. 4, pp. 23-44.

Lorenzoni, G. and Lipparini, A.. 1999, The Leveraging of Interfirm Relationships as a Distinctive Organizational Capability: A longitudinal study, Strategic Management Journal, Vol. 20, No. 4, pp. 317-338.

Magnusson, J. and Nilsson, A. 2003, To Facilitate Or Intervene - A Study of Knowledge Management Practice in SME Networks", Journal of Knowledge Management Practice, Vol. 4. http:/ / www.tlainc.com/articl48.htm, read September 15. 2011.

Phillips, L.D. and Phillips, M.C. 1993. Facilitated work groups - Theory and practice, Journal of the Operational Research Society, Vol. 44, pp. 533-549.

Sawhney, M. and Prandelli, E. 2000, Communities of creation: managing distributed innovation in turbulent markets, California Management Review, Vol. 42, No. 4, pp. 24-54.

Shahriza, N., Karim, A. and Heckman, R. Group communication media choice and the use of information and communication technology to support learning: a case study, Campus-Wide Information Systems, Vol. 22, No. 1, 2005, pp. 28-42.

Simatupang, T.M., Wright, A.C. and Sridharan, R. 2002, The knowledge of coordination for supply chain integration, Business Process Management Journal, Vol. 8, No. 3, pp. 289-308.

Studt, T. 2004, The 10 rules of technology transfer, R\&D Magazine, Vol. 46, No. 2, pp. 36-38.

Sundgren, M., Dimenaes, E., Gustafson, J.E. and Selart, M. 2005, Drivers of organizational creativity: a path model of creative climate in pharmaceutical R\&D, R\&D Management, Vol. 35, pp. 59-374.

Tsai, W. and Ghoshal, S. 1998, Social capital and value creation: the role of intrafirm networks. Academy of Management Journal, Vol. 41, pp. 464-476.

Walker, A. and Ellis, H. 2000, Technology transfer: strategy, management, process and inhibiting factors, International Journal of Innovation Management, Vol. 4, No. 1, pp. 97-122. 


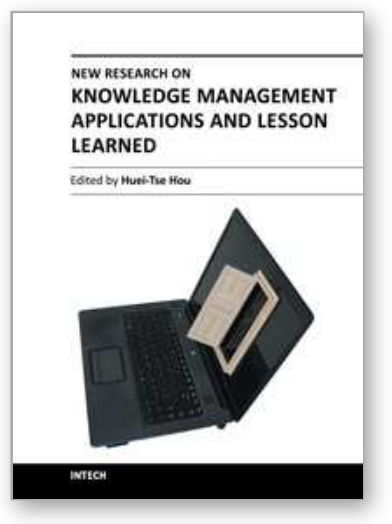

\author{
New Research on Knowledge Management Applications and \\ Lesson Learned \\ Edited by Dr. Huei Tse Hou
}

ISBN 978-953-51-0073-7

Hard cover, 242 pages

Publisher InTech

Published online 02, March, 2012

Published in print edition March, 2012

Due to the development of mobile and Web 2.0 technology, knowledge transfer, storage and retrieval have become much more rapid. In recent years, there have been more and more new and interesting findings in the research field of knowledge management. This book aims to introduce readers to the recent research topics, it is titled "New Research on Knowledge Management Applications and Lesson Learned" and includes 14 chapters. This book focuses on introducing the applications of $\mathrm{KM}$ technologies and methods to various fields. It shares the practical experiences and limitations of those applications. It is expected that this book provides relevant information about new research trends in comprehensive and novel knowledge management studies, and that it serves as an important resource for researchers, teachers and students, and for the development of practices in the knowledge management field.

\title{
How to reference
}

In order to correctly reference this scholarly work, feel free to copy and paste the following:

Erno Salmela and Ari Happonen (2012). Applying Social Media in Collaborative Brainstorming and Creation of Common Understanding Between Independent Organizations, New Research on Knowledge Management Applications and Lesson Learned, Dr. Huei Tse Hou (Ed.), ISBN: 978-953-51-0073-7, InTech, Available from: http://www.intechopen.com/books/new-research-on-knowledge-management-applications-and-lessonlearned/applying-social-media-in-collaborative-brainstorming-and-creation-of-common-understandingbetween-in

\section{INTECH}

open science | open minds

\section{InTech Europe}

University Campus STeP Ri

Slavka Krautzeka 83/A

51000 Rijeka, Croatia

Phone: +385 (51) 770447

Fax: +385 (51) 686166

www.intechopen.com

\section{InTech China}

Unit 405, Office Block, Hotel Equatorial Shanghai

No.65, Yan An Road (West), Shanghai, 200040, China

中国上海市延安西路65号上海国际贵都大饭店办公楼 405 单元

Phone: +86-21-62489820

Fax: $+86-21-62489821$ 
(C) 2012 The Author(s). Licensee IntechOpen. This is an open access article distributed under the terms of the Creative Commons Attribution 3.0 License, which permits unrestricted use, distribution, and reproduction in any medium, provided the original work is properly cited. 